\title{
El cuerpo como medio de expresión y como instrumento de trabajo: dualismos persistentes en el mundo de la danza*
}

THE BODY AS A MEANS OF EXPRESSION AND AS A MEANS OF LABOR: A

PERSISTENT DUALISM IN THE WORLD OF DANCE

O CORPO COMO UM MEIO DE EXPRESSÃO E COMO UM MEIO DE TRABALHO:

DUALISMO PERSISTENTE NO MUNDO DA DANÇA

\section{Ana Sabrina Mora**}

Cuadernos de Música, Artes Visuales y Artes Escénicas

/ Volumen 10 - Número 1 / enero - junio de 2015 /

ISSN 1794-6670/ Bogotá, D.C., Colombia / pp. 115-128

Fecha de recepción: 26 de agosto de 2014 | Fecha de aceptación: 24 de octubre de 2014 | Disponible en línea: 29 de mayo de 2015. Encuentre este artículo en http:// cuadernosmusicayartes.javeriana.edu.co/

doi:10.11144/Javeriana.mavae10-1.cmei

* Esta investigación fue llevada a cabo en el marco de la realización de mis estudios de doctorado, que culminé en marzo de 2011. La tesis completa se encuentra disponible para acceso público en el repositorio digital institucional de la Universidad Nacional de La Plata (UNLP), Argentina

* * Investigadora del Consejo Nacional de Investigaciones Científicas y Técnicas (CONICET, Argentina) con lugar de trabajo en el CICES-IdIHCS-UNLP/CONICET. Docente de la Licenciatura en Antropología de la Universidad Nacional de la Plata (UNLP), Buenos Aires, Argentina 


\section{Resumen:}

En este artículo se ponen en discusión parte de los resultados de una investigación etnográfica acerca de la construcción del cuerpo y de subjetividades durante la formación en danza clásica, danza contemporánea y expresión corporal. En primer lugar, se presentan los fundamentos de algunas de las decisiones tomadas durante el proceso de investigación. En segundo lugar, se sintetizan las diferencias más sobresalientes en los modos de transmisión de las tres danzas estudiadas, para luego analizar algunos elementos que tienen en común entre ellos. En tercer lugar, se destaca un punto convergente a pesar de las diferencias: la vigencia de las concepciones dualistas sobre el cuerpo y el sujeto.

Palabras clave: danza; cuerpo; sujeto; dualismo; etnografía

\begin{abstract}
:
This article discusses some of the results of an ethnographic study about body building and subjectivities during the formation in classical dance, contemporary dance and bodily expression. First, the basics of some of the decisions made during the research process are presented. Secondly, the salient differences in the modes of transmission of the three dances studied were synthesized and then some elements in common are analyzed. In the third place, a point that appears in common despite the differences is highlighted: notions about the life of the body that speak of the persistence of dualistic conceptions of the body and the subject.
\end{abstract}

Keywords: dance; body; subject; dualism; ethnography

\section{Resumo:}

Este artigo é colocado em discussão sobre os resultados de um estudo etnográfico sobre a construção do corpo e de subjetividades durante a formação em dança clássica, dança contemporânea e expressão corporal. Primeiro algumas das decisões tomadas durante o processo de pesquisa são apresentados. Em segundo lugar, as diferenças marcantes nas formas de transmissão das três danças estudados foram sintetizados e, em seguida, analisar alguns elementos em comum. Em terceiro lugar, é apontado uma questão que aparece em comum, apesar das diferenças destacadas: noções sobre a vida do corpo que falar da persistência de concepções dualistas do corpo e do sujeito.

Palavras-chave: dança; corpo; sujeito; dualismo; etnografia 


\section{INVESTIGAR Y EXPERIMENTAR: CUANDO EL CUERPO Y LA DANZA NO SE DESVANECEN EN EL AIRE}

En el primer capítulo de Paths toward a clearing (1989), Michael Jackson, parafraseando a Michel Foucault, describe al ser humano como "un rostro de arena en los límites del mar" (2008 [1966], p.375). Leí este texto cuando estaba iniciando una investigación etnográfica que desarrollé entre 2005 y 2010 en la Escuela de Danzas Clásicas de La Plata (Argentina), donde se cursan carreras de intérprete-bailarín y de profesor en danzas clásicas, danza contemporánea y expresión corporal. La imagen del dibujo en la arena me recordó otra que me había impresionado mucho cuando comenzaba a cursar la licenciatura en antropología: las huellas de Laetoli, en África, dejadas por dos personas que caminaban quién sabe hacia dónde, quién sabe por qué, quién sabe cómo, pero que, por azares climáticos y geográficos pudieron ser encontradas casi cuatro millones de años después. Estas huellas fueron para mí la prueba de que lo efímero puede también ser eterno, y de que lo más inasible también puede ser revelador $-\mathrm{y}$ revelado-.

Al recordar esas huellas, pensé que la danza es una huella en la arena y que las experiencias vividas en torno a ella, también lo son. La danza, tan poco objetivable, tan difícil de asir y tan efímera, se transmite, se aprende y se experimenta desde la potencia del cuerpo, desde lo que el cuerpo, también tan difícil de asir, es capaz de hacer. Lo que el cuerpo hace se nos suele escapar, porque no siempre podemos articular su evidencia material y experiencial en términos del lenguaje o porque no siempre tenemos la manera o las palabras para traducir el experimentar en decir. A partir de este punto, se planteó un primer desafío en mi investigación: ¿cómo hacer para conocer la corporalidad de otro en un trabajo etnográfico? La primera pregunta metodológica fue, en este sentido, si alcanzaría con describir los cuerpos que podía observar en el transcurso de las clases, los ensayos, las funciones, los tiempos de espera, las interacciones cotidianas. La respuesta que le di a esto fue que no, porque el cuerpo no es solo exterioridad. ¿Alcanzaría entonces con preguntarle cosas a ese otro? Tampoco; el cuerpo no es solo lo que podemos decir sobre él. Ambas cosas; la observación y las entrevistas para conocer la perspectiva de los otros, eran indudablemente útiles. Pero también entendí que resultaría útil incluir mi propia experiencia, con el relato de aquello que me llegaba desde mi propio cuerpo inmerso en la práctica de la danza.

En este punto, quedó planteado un segundo desafío: ¿cómo hacer para captar la huella en la arena de mi propia experiencia y congelarla en un escrito académico? ¿Cómo convertir mi experiencia en un dato de utilidad para mi investigación? A grandes rasgos, la utilidad estuvo dada en la apuesta misma por realizar una práctica de conocimiento corporizada, abierta a la dimensión encarnada que tiene toda acción de producción de conocimiento. De modo más específico, la problematización de mi propia experiencia fue un camino para comprender la corporalidad de otros, para interpretar lo que me contaban y lo que veía, para pensar preguntas de investigación. Aparecía, así, una nueva huella: la huella en la arena de la experiencia del cuerpo propio y de los otros, que debía congelar y captar para luego desenterrarla meticulosamente y recuperarla, con el fin de que pudiera ser plasmada en un escrito académico descorporizado.

Para esta investigación, ni la danza, ni el cuerpo fueron considerados inaprensibles o inabordables. Construimos un conjunto de herramientas metodológicas que incluyeron las técnicas de recolección de datos de las que disponía como antropóloga (observación participante y distintos tipos de entrevistas), técnicas de corte cuantitativo (una encuesta), y mi propia ob- 
servación participante como practicante de las danzas sobre las que estaba investigando. Los cuerpos y las subjetividades de mis informantes/interlocutores estaban allí. No sabía exactamente cómo llegar a ellos, pero podía anticipar que debía haber un modo de llegar. Finalmente, el solo hecho de prestar atención a nuestro objeto de estudio, que era una práctica donde el cuerpo y la corporalidad ocupan el lugar central, me llevó a pensar que el cuerpo también debe ser central desde el punto de vista metodológico y no solo un recurso teórico-conceptual. El cuerpo era a la vez camino, punto de partida y lugar de llegada.

La danza suele ser caracterizada haciendo hincapié en su inmediatez. Las danzas que consideré en mi tesis de doctorado se definen como prácticas artísticas, es decir, forman parte del campo del arte. En los tratados que la analizan en relación con las otras artes, aquella es la característica más señalada. A la vez, es algo que comparte con otras formas de danza que no se definen a sí mismas como formas de arte. Más allá de reconocer que toda obra de arte es modificada en el fluir del tiempo y en las distintas miradas (u otros sentidos) que se pongan en ellas -mientras que las artes visuales o la literatura, por ejemplo, se presentan en un producto objetivado, que permanece más allá del momento en el que es producido- una obra de danza tiene lugar solamente en el espacio y en el tiempo en que está siendo bailada. Aunque existen sistemas de notación para las coreografías, que cumplirían la función de los guiones o de las partituras musicales, su uso no es generalizado. Como todas las artes actuales, la danza presenta la posibilidad de su reproductibilidad, simplemente porque una obra de danza puede ser filmada; pero este registro no es la obra en sí, no es el producto de la práctica artística -salvando el caso de la video-danza, cuyo resultado, o al menos una parte importante de él, es una filmación-. Aunque las coreografías pueden repetirse, la impredictibilidad y el carácter esencialmente cambiante de los cuerpos, hacen que nunca se dé de forma exactamente igual cuando se repite.

En cierto modo, toda práctica corporal es efímera; es siempre un hacer que se desarrolla en un espacio y en un tiempo y existe en un actuar. Pero, por otro lado, toda práctica corporal deja huellas en el cuerpo, ya sea a manera de inscripciones concretas -como las escoriaciones, las deformaciones craneales intencionales o los tatuajes- o en forma de un determinado habitus o una determinada corporización. ¿Cuál es la especificidad de la danza entre otras prácticas de este tipo?, ¿cuál es la huella, el rastro, que me interesaba destacar en mi investigación?

Por un lado, las danzas no se desarrollan de manera aislada: son producto y productoras de fenómenos socio-culturales. En los distintos desarrollos de la antropología de la danza, desde su surgimiento como campo de estudios en los sesenta, se ha partido de que las danzas son producto de contextos históricos y sistemas socio-culturales específicos. Por esto, la investigación sobre cualquier danza es un aporte para la comprensión de la totalidad sociocultural de la que forma parte.

Por otro lado, la danza- supuestamente efímera- dejaba huellas difíciles de borrar en los cuerpos y en las subjetividades de las personas con quienes realicé mi trabajo de campo etnográfico. Entrevista tras entrevista, estas huellas aparecían y se mostraban en toda su intensidad, a veces en marcas difíciles de borrar, en proyecciones múltiples e inesperadas. Esto fue lo que me interesó explorar.

La investigación de la que he extraído el eje analítico de este artículo estuvo basada en una etnografía sobre la formación en danza clásica, danza contemporánea y expresión corporal, partiendo de una perspectiva de análisis que conjugó cuerpo y danza, desde un enfoque 
que dialogó principalmente con la antropología del cuerpo- puesto que la atención no estuvo puesta tanto en las danzas en sí mismas como en las prácticas y usos del cuerpo durante ese proceso, en las experiencias que se tienen en relación con el aprendizaje de la danza y en las representaciones sobre el cuerpo propio, el cuerpo de los otros y el cuerpo de la danza que las y los estudiantes ponen en juego-. De cualquier modo, el diálogo con la antropología de la danza no estuvo ausente, en especial con las líneas que estudian la danza y el movimiento, en relación con un contexto social y cultural con unas representaciones sobre el cuerpo, prácticas corporales y experiencias corporizadas.

Cuando una investigación se enfoca en la construcción particular de los cuerpos que tiene lugar en la danza, es posible conocer las representaciones y significaciones asociadas al cuerpo, las prácticas y los usos concretos vinculados a él y las experiencias corporales que se dan en esa práctica concreta. Por medio suyo también es posible acceder a algunas representaciones, prácticas y experiencias del cuerpo posibles dentro de un contexto sociocultural. Estas dos dimensiones -el carácter socio-culturalmente situado de las danzas y los distintos aspectos de la construcción del cuerpo que propician- han sido las claves centrales que hemos tomado en cuenta en nuestro trabajo.

En este artículo presentaré una parte de los resultados que he obtenido en la indagación acerca de las prácticas, representaciones y experiencias puestas en juego durante la formación en las danzas que ya he mencionado. No me detendré aquí en los principios y fundamentos de estas diferentes danzas, en la dinámica institucional, intersubjetiva e intercorporal, en el complejo universo de representaciones que en ellas están vigentes ni detallaré las modalidades y lógicas enseñanza-aprendizaje -aunque estas cuestiones sí formaron parte de mi tesis doctoral-. Sintetizaré las diferencias más sobresalientes en los modos de transmisión de las tres danzas, para destacar un punto que aparece en común, a pesar de las diferencias: la vigencia de las concepciones dualistas sobre el cuerpo y el sujeto.

\section{ENSEÑAR Y APRENDER DANZA: ENTRE LA IMITACIÓN DE FORMAS Y LA EXPLORACIÓN DE LAS POSIBILIDADES DEL CUERPO EN MOVIMIENTO}

El ballet es vestir, con movimientos ordenados, un pensamiento de ensueño. Unir a la poesía del desarrollo lineal la pasión de la estructura llevada a la realidad escénica.

(Dora Kriner, 1964, p.11)

Mi arte es precisamente un esfuerzo que tiende a expresar, con gestos y movimientos, la verdad de mi ser. (...) Desde el primer momento, no he hecho sino bailar mi vida. De niña bailaba el gozo espontáneo de las cosas que crecían. (...) Mi primera idea del movimiento y de la danza me ha venido seguramente del ritmo de las olas. (...) A esta vida salvaje y sin obstáculos de mi niñez, debo la inspiración de la danza que he creado y que no es sino la expresión de la libertad.

(Duncan, 1985 [1921], p. 40, 48 y 49) 
La danza moderna es una nueva forma de expresión, tan llena de valiosos hallazgos en movimientos puros, $y$ tan representativa de todo aquello que la actual generación desea transmitir. Debemos danzar como somos, como sentimos, y con las reacciones provocadas por la Vida que nos rodea.

(Itelman. 2002, p.24)

La danza no es sólo un arte, es un modo de vivir, un modo de existir.

(Stokoe, 1990, p. 61)

Los epígrafes que abren este apartado dan cuenta de la diversidad de concepciones sobre la danza que aparecen en las carreras que conviven dentro de la Escuela de Danzas Clásicas de La Plata. Siguiendo estas concepciones, los modos de incorporación de estas danzas se distinguen según los criterios que manejan acerca del cuerpo y del movimiento. Las características particulares de cada modo de entender la danza tienen su correlato en los modos en que es enseñada, en los modos en que se hace cuerpo.

La construcción del cuerpo para el movimiento en la danza se realiza incorporando habilidades, técnicas y hábitos con un fin expresivo. A lo largo del proceso de formación de bailarinas y bailarines - de profesores y profesoras en danzas- se construyen modos particulares de corporalidad y de subjetividad; se internalizan las reglas de juego de la institución y del campo de la danza. Esto ocurre porque en la formación confluyen tanto las condiciones objetivas del campo en que se desarrollan las prácticas, como las concepciones de la danza y el cuerpo características de cada danza particular. Las y los jóvenes que aprenden y practican las diferentes formas de danza incorporan tradiciones artísticas que conllevan visiones del cuerpo, del movimiento, por lo tanto, del sujeto. A la vez, incorporan disposiciones que son particulares de su campo, necesarias para ingresar y permanecer en él. Todas estas tradiciones y disposiciones se recrean, apropian, resignifican y actualizan en el presente, son vividas cotidianamente en las clases, los ensayos, las decisiones que se toman en relación a los espectáculos, las experiencias que viven y los modos en que experimentan sus cuerpos. Las bailarinas y los bailarines en formación se juzgan a sí mismos y juzgan a los otros en relación con los principios que definen a su danza -tal como son entendidos estos principios por los agentes de la institución-y de acuerdo al grado de adecuación de sus cuerpos y capacidades de movimiento ante estos requerimientos.

El entrenamiento en las danzas significa una inversión corporal en el tiempo, una "somatización lenta" -o incorporación, en el sentido de 'hacer cuerpo'- de los principios y las técnicas de estas prácticas corporales, que van formando bailarinas y bailarines en una serie de disposiciones.

Para comprender los procesos de formación y los modos de transmisión de las danzas, realizamos observaciones de clases, ensayos, muestras y actos artísticos en ceremonias de graduación. Se tomaron en cuenta documentos escritos producidos en el contexto de los procesos de enseñanza-aprendizaje. Estos materiales fueron también vinculados con entrevistas acerca de las trayectorias de formación, las estrategias y prácticas de enseñanza de los docentes, y los recuerdos, percepciones y opiniones de los estudiantes.

En el recorrido por las diversas modalidades de enseñanza que se dan en todas las carreras, consideramos desde los momentos de ingreso hasta la elaboración y presentación de 
las tesis de fin de carrera y las ceremonias de grado, pasando por las distintas formas de dar clases, de determinar qué es lo que debe enseñarse, de tomar exámenes y de producir espectáculos. La preocupación que guió todo este recorrido fue conocer cómo eran transmitidas las diferentes formas de danza, los modos en que se daba, en la práctica, la formación en danzas, cómo se realizaba la educación y la producción de los cuerpos para el movimiento, cuáles eran las distintas formas que puede tomar esta transmisión, cuáles eran las regularidades más allá de estas diferencias y, finalmente, qué cuerpos eran construidos y qué construcción de subjetividades propiciaba esa construcción de corporalidades. Cada una de las danzas que consideramos posee un conjunto de procedimientos y lógicas de entrenamiento característicos, de acuerdo a sus principios, fundamentos y objetivos.

LaTecnicatura y Profesorado en Danzas Clásicas comprende un año de ciclo preparatorio, tres de ciclo de iniciación, tres de ciclo medio y cuatro de profesorado. El ingreso se realiza entre los 8 y los 12 años. Este inicio temprano se basa en la creencia de que el carácter de la técnica clásica hace necesario su aprendizaje desde la infancia. Actualmente se realiza una evaluación diagnóstica inicial, que ha reemplazado la evaluación eliminatoria que se hacía hasta los ochenta. Estas evaluaciones, ya sean eliminatorias o diagnósticas, se hacen desde posicionamientos más o menos rígidos, pero por lo general, se sustentan en la creencia de que no todas las formas, proporciones y capacidades corporales pueden incorporar por completo la técnica clásica. En ese momento se evalúan las 'condiciones' para la práctica, que comprenden características somáticas, condiciones funcionales y capacidades de ejecución. En función del cumplimiento de una serie de estas características, se conforma una jerarquía basada en la idea de que cuantas más condiciones se posean, más posibilidades se tendrá de incorporar la técnica clásica.

En danzas clásicas, desde las primeras clases hasta las de los profesionales, se mantiene la misma estructura: un primer fragmento de la clase en la barra -donde se trabaja el equilibrio y se realizan ejercicios de calentamiento y de estiramiento-, un segundo fragmento en el centro -donde se ejercita el equilibrio y la alineación, y se trabaja progresivamente en la calidad de los movimientos, tanto lentos como en velocidad, terminando con giros y saltos- y un saludo final. Recordemos que la técnica clásica está constituida por una serie limitada de posturas, pasos y movimientos, cada uno de ellos con un nombre y un modo unívoco de ejecución. Para formarse como bailarina o bailarín de danzas clásicas, la formación consiste en un entrenamiento a largo plazo, graduado, sistemático y basado en el control cronométrico y milimétrico del cuerpo en sus diferentes fragmentos, haciendo entrar paulatinamente a ese cuerpo dentro de una técnica, un modelo de movimiento y un modo de acción específicos. Cabe aclarar que estas clases son, en gran parte, diferenciales para mujeres y para varones. A grandes rasgos, pudimos describir dos modalidades de enseñanza de la técnica: una de ellas, la más tradicional, parte eminentemente de la imitación y la copia de formas, pasos y movimientos; la otra, más reciente, toma como punto de partida el conocimiento de la biomecánica de los movimientos y el reconocimiento del propio cuerpo, aunque ambas comparten el mismo objetivo de lograr la incorporación de la técnica específica.

La Tecnicatura y Profesorado en Danza Contemporánea comprende tres años de formación básica, dos años de ciclo de tecnicatura y cuatro años de profesorado. Se permite ingresar al primer año de formación básica entre los 15 y los 22 años, pasando por un taller de ingreso donde se ofrecen clases de las distintas áreas y se dan charlas explicativas sobre la carrera, la institución y el cuidado de la salud. En esta carrera, el principio de enseñanza más di- 
fundido busca comprender el movimiento 'desde el interior del cuerpo', refiriéndose con esto al reconocimiento de la biomecánica y la propiocepción. La explicación que suele ofrecerse acerca de este modo es que "no es posible bailar sin conocer el cuerpo". Por este medio se busca el aprendizaje y el despliegue de los diferentes elementos del movimiento y de diversas modalidades de ejecución.

Las clases prácticas de danza contemporánea pueden dividirse en clases de técnica moderna o contemporánea y clases de improvisación y composición. En las primeras se trabaja, generalmente, a partir del aprendizaje de secuencias de movimiento propias de distintas técnicas, utilizando tanto la imitación, como el contacto corporal y la exploración de las posibilidades de movimiento de cada estudiante, buscando siempre la extensión de esas capacidades. En las del segundo tipo se suele partir de una consigna inicial que se va desarrollando y modificando, sin necesidad de ajustarse a una determinada secuencia -aunque comúnmente se utilizan secuencias aprendidas en otras clases- o a un solo lenguaje o técnica.

El Profesorado en Danza-Expresión Corporal comprende un año de formación básica y cuatro años de profesorado. El ingreso se puede hacer sin límite de edad, solo existe el requisito de haber completado la educación secundaria. Esta carrera fue diseñada por completo tomando en cuenta los requerimientos de la DGCyE provincial, y desde su inicio fue pensada para cubrir los cargos docentes en la asignatura de "danza" que existía en las escuelas del sistema -y que hasta ese momento cubrían solo los docentes graduados de los Profesorados provinciales en Danzas Tradicionales Argentinas-. Esta incumbencia laboral la hace diferente de la otras dos carreras de la EDCLP, cuyos títulos no habilitan a los graduados a dar clases en las escuelas del sistema, sino solo en los terciarios de educación artística. Esto último, sumado a que es la última carrera que ha llegado a la institución y a que es la de menor duración, es fuente de recelo y conflicto en la relación entre las carreras.

La enseñanza-aprendizaje se aborda buscando y partiendo del conocimiento del propio cuerpo, por medio de distintas estrategias como la conciencia corporal, la sensopercepción, etc. Las clases se desarrollan con base en una improvisación orientada y pautada, que puede incluir el análisis del movimiento y la promoción del movimiento a partir de estímulos -surgidos del propio cuerpo, del contacto con otros y del entorno, etc.-. El objetivo final es construir un lenguaje corporal propio - un lenguaje propio de movimiento-y potenciar la expresión.

Mientras en las carreras de danzas clásicas y de danza contemporánea la formación se completa con la práctica escénica en el marco de los tres Ballets de la institución -que cuenta con un Ballet Infantil, un Ballet Clásico y un reciente Ballet Contemporáneo-, la carrera de danza-expresión corporal no cuenta con uno. De todos modos, en todas las carreras se realizan periódicamente muestras de trabajos producidos en distintas cátedras. Y las tres carreras exigen, para la graduación, la elaboración de una obra coreográfica completa, que se presenta a fin de año. Algunas de ellas se seleccionan para ser presentadas en la ceremonia de grado.

Luego de describir las diferencias entre las distintas orientaciones, rescatamos algunos elementos que tienen en común las múltiples formas de enseñar y aprender las danzas que consideramos. Uno de estos elementos es que, con el entrenamiento, se pretende lograr la somatización de los principios y las técnicas de las danzas. En otras palabras, se busca que el cuerpo 'entre' en la práctica y la práctica 'entre' en el cuerpo, incluyendo la incorporación de un determinado habitus junto con las habilidades necesarias para cada danza.

Otros elementos en común entre las distintas carreras nos permitieron configurar dos modos centrales en los que se logra esta incorporación: un modo de transmisión cuerpo a 
cuerpo, y un modo de transmisión cuerpo-palabra-cuerpo. La llegada al cuerpo de cada alumno ocurre de estos dos modos simultáneamente, aunque uno u otro puede prevalecer en distintas situaciones y contextos.

El modo de transmisión cuerpo a cuerpo sucede con la intervención del contacto físico y de la mirada. En las clases de técnica de las distintas danzas, los docentes muestran, con sus propios cuerpos, las posturas y los pasos, para que el movimiento pueda incorporarse y realizarse adecuadamente. También realizan correcciones y demostraciones utilizando el contacto y la dirección de su propio cuerpo sobre el de los alumnos. Además, no solo interviene la mirada del alumno sobre el docente y la del docente sobre el alumno; también lo hace la mirada entre compañeros.

El modo de transmisión cuerpo-palabra-cuerpo implica, como es de suponerse, la mediación de la palabra entre los cuerpos. Lo que se dice proviene de una incorporación ya realizada, y se dirige a conseguir que quien escucha logre que su cuerpo comprenda qué hacer. Es decir, se habla para que lo dicho llegue al cuerpo de otro. En general, con las palabras se refuerza lo que se muestra, y con ellas se busca la internalización de imágenes que se trasladarán al cuerpo. Hay explicaciones, indicaciones, correcciones y relatos realizados por docentes y conversaciones y comentarios entre estudiantes. En el proceso de enseñanza, la transmisión corporal del movimiento está acompañada de palabras en distintos momentos: cuando se nombran pasos, secuencias o modos ya aprendidos y que tienen un determinada denominación o que ya se han practicado, por lo que se puede decir, por ejemplo "como hicieron la clase pasada." De esta manera se utiliza el lenguaje de la anatomía para conocer la biomecánica que permitirá realizar los complicados movimientos, buscando el conocimiento del propio cuerpo para poder controlarlo y se dan consignas en formas de comparaciones metafóricas, por ejemplo: "muevan sus brazos como si fueran cisnes", "caminen como si una cuerda las tirara hacia arriba". Con las palabras se refuerza lo que el o la docente muestra, y con ellas se busca la internalización de imágenes que se trasladarán al cuerpo. La particularidad de este uso de la palabra es que lo que se dice, proviene de una incorporación ya realizada, y se dirige a conseguir que quien escuche, logre que su cuerpo comprenda qué hacer.

Esta distinción entre dos modos generales de transmisión es puramente analítica; no solo porque ambos modos coexisten en una misma clase, en una misma práctica docente, sino porque la palabra es también cuerpo. No se trata solo de lo que se dice, sino de la intervención de la voz de el o la docente, es decir, de algo que también es parte de su cuerpo, con el tono, calidad y color de la voz, con su carga emocional. Además, no se emiten solo palabras, sino también sonidos que marcan ritmos, usando no solamente la voz sino partes de su cuerpo como las palmas- o la interacción entre su cuerpo y algún objeto -por ejemplo, golpeando los pies contra la madera del piso- o varias de estas cosas al mismo tiempo. Por último, aunque hay partes de la clase donde solo se utiliza la imitación o el contacto corporal, no se está ante cuerpos mudos: se escuchan continuamente sonidos que provienen de los mismos cuerpos, y también se escucha música, producida dentro del salón o en otros salones de la escuela.

Al ser una práctica que se inscribe en el cuerpo, la danza implica conocer y comprender el propio cuerpo y sus modos de relacionarse con el espacio, con el tiempo, con los estímulos externos e internos, con los otros con quienes se comparte un entorno, y también implica modificar la relación que se establece con el cuerpo y aprender cómo trabajarlo y usarlo como medio expresivo. Es una actividad que se centra en una comprensión del propio cuerpo y en la modificación de la relación que se establece con él. El fin último es transmitir un saber cor- 
poral, que será aprendido en tanto sea incorporado, es decir, en tanto quede hecho cuerpo.

El modo de enseñanza de las danzas escénicas occidentales puede ir desde la búsqueda de su control y de la incorporación de una técnica estricta que modifica sus formas 'naturales', hasta los métodos para el conocimiento del propio cuerpo y sus posibilidades expresivas, pasando por el conocimiento de las posibilidades de movimiento del propio cuerpo para incorporar nuevas técnicas o modos de movimiento. Las técnicas de aprendizaje son diversas: imitación, copia de formas y secuencias de movimiento preestablecidas; exploración, reconocimiento de la anatomía, la biomecánica e improvisación pautada, entre las más importantes -ya sea para lograr moverse de acuerdo con técnicas específicas o para explorar y desplegar desde allí las posibilidades de movimiento-. Aunque no es poco frecuente que estas técnicas se utilicen de modo combinado en clases de las distintas danzas, cada una posee un conjunto de procedimientos y lógicas de entrenamiento característicos, de acuerdo con los principios y fundamentos que las sustentan como también, los objetivos de cada una.

El entrenamiento en la danza significa una inversión corporal en el tiempo. La somatización de los principios y las técnicas de las prácticas corporales es un proceso lento; por esto, el entrenamiento es repetitivo, continuo, agotador, plagado de ejercicios que a veces recuerdan solo remotamente lo que luego se hará en una secuencia o en el escenario, sostenidos por la creencia común de que lo que ocurrirá en estos puntos de llegada depende directamente de lo que se haga durante el entrenamiento intenso. La monotonía del entrenamiento se mantiene no solo con la promesa de los logros futuros, sino que también procura pequeños placeres: la camaradería, el hecho de estar haciendo algo que permite olvidar los problemas cotidianos, sentir como el cuerpo cambia, que se lo logra controlar y dominar para hacer siempre cosas nuevas, que el cuerpo "se hace" poco a poco a la disciplina y a la técnica que se le impone.

En suma, formarse en una danza no implica solamente aprender la manera de ejecutar ciertos movimientos, sino también incorporar un conjunto de disposiciones que dejarán su huella -con la mediación de otras huellas- en los cuerpos y en las subjetividades.

\section{EL CUERPO EN LA DANZA: MEDIO, INSTRUMENTO Y MÁS}

Entre la construcción particular de los cuerpos que se da durante la formación en danzas clásicas, danza contemporánea y danza-expresión corporal, hemos encontrado un elemento que atraviesa a estas tres carreras: la concepción del cuerpo como medio y como instrumento, en particular como medio de expresión e instrumento de trabajo. Esta visión ha sido recurrente en los discursos de las y los estudiantes y docentes de la Escuela de Danzas Clásicas de La Plata, y también está presente en los escritos de teoría de la danza o en las biografías de figuras del campo. Por ejemplo, la destacada creadora de danza moderna Martha Graham ha escrito que "el instrumento mediante el que se expresa la danza es también el instrumento mediante el que se vive la vida: el cuerpo humano" (1995 [1991], p.30). O, en palabras de Ana Itelman, bailarina, coreógrafa y maestra de danza, pionera en la danza moderna en Argentina, la danza es movimiento expresivo del cuerpo humano, utiliza el más humano de todos los instrumentos para su expresión, [y esto le da su característica distintiva] el instrumento y el intérprete son uno sólo" (2002, p. 25).

Estas nociones implican modos de entender el cuerpo, de vivirlo, de sentirlo, de verse en relación con él, de cuidarlo, de modificarlo, de hacerse un cuerpo, de hacerse sujeto en relación con él y de producirse a sí mismo como sujeto en relación con experiencias del cuerpo. 
Es decir, el cuerpo como medio y como instrumento constituye un modo de representarlo, configura la realización de ciertas prácticas y enmarca maneras de experimentarlo.

La visión del cuerpo como instrumento es compatible con una noción de cuerpo que lo asimila a un objeto, y en particular a un objeto que se puede manipular para lograr un fin, cuya función preponderante es ser manipulado. Se trata de un cuerpo que se controla, que es posible controlar y que se debe controlar para lograr un fin. Un cuerpo que puede transformarse en un obstáculo cuando no se logra controlar.

El carácter de instrumento de trabajo es evocado usualmente al momento de hablar acerca del cuidado del cuerpo, cualesquiera que sean las prácticas involucradas en ese cuidado: supresión de determinados alimentos, realización regular de actividad física, preocupación por la salud, prevención de lesiones, escucha de las necesidades y los tiempos del cuerpo, entre otras. Ante la pregunta por los motivos de estos cuidados, la respuesta suele ser "porque el cuerpo es mi instrumento de trabajo" o "porque el cuerpo es el instrumento de trabajo del bailarín".

Asimismo, podemos ver esto en las respuestas a algunas de las preguntas que conformaban la encuesta -uno de los instrumentos utilizados durante el trabajo de campo, junto con entrevistas en profundidad, entrevistas grupales y observaciones participantes-, realizada a más de un centenar de estudiantes de las tres carreras de la EDCLP. A la pregunta: “¿Hay circunstancias en las que sentís que tu cuerpo es un obstáculo?", con las opciones de respuesta "si no", el porcentaje de respuestas positivas fue del 34\% para danza-expresión corporal, $46 \%$ para danzas clásicas y $56 \%$ para danza contemporánea. Ante la pregunta que le sigue, "¿En qué circunstancias?", la mayoría de las respuestas apuntan a momentos en que no se logran incorporar elementos de las técnicas de danza o no se logran realizar determinados movimientos y a la percepción de limitaciones anatómicas o bio-mecánicas del propio cuerpo. Es decir, el cuerpo aparece como un obstáculo cuando se lo percibe como límite, cuando su materialidad no permite hacer lo que se quiere hacer.

El último ítem de la misma encuesta proporcionaba una lista de afirmaciones, ante las cuales quien respondía debía indicar si estaba con cada una de ellas totalmente de acuerdo, de acuerdo en parte o totalmente en desacuerdo. Algunas de estas afirmaciones apuntaban a conocer en qué grado existía la concepción del cuerpo como un instrumento y como algo que controlar -concepción que ya habíamos encontrado en varias entrevistas a docentes y a estudiantes de la institución-. Prevalecieron ampliamente las opciones positivas en las frases que afirmaban el carácter del cuerpo y sus recursos como instrumentos a utilizar:

- Con respecto a "Utilizo mi cuerpo como un instrumento", aproximadamente el 57\% marcaron la opción "estoy totalmente de acuerdo", 35\% "estoy de acuerdo en parte" y $4 \%$ "estoy en desacuerdo".

- Con respecto a "Debemos utilizar el cuerpo al máximo de sus posibilidades", aproximadamente 54\% marcaron la opción "estoy totalmente de acuerdo", 38\% "estoy de acuerdo en parte" y $6 \%$ "estoy en desacuerdo".

- Con respecto a "Conozco los recursos que posee mi cuerpo", aproximadamente $36 \%$ marcaron la opción "estoy totalmente de acuerdo", $59 \%$ "estoy de acuerdo en parte" y $2 \%$ "estoy en desacuerdo".

Recíprocamente, fueron mucho menos frecuentes los acuerdos totales y mucho más frecuentes los desacuerdos con las afirmaciones que planteaban que el cuerpo tiene dimensiones que no es posible o no es deseable controlar: 
- Con respecto a "El cuerpo tiene toda una vida espontánea que no podemos controlar", aproximadamente $24 \%$ marcaron la opción "estoy totalmente de acuerdo", 49\% "estoy de acuerdo en parte" y $20 \%$ "estoy en desacuerdo".

- Con respecto a "No pienso en utilizar mi cuerpo, sólo lo vivo", aproximadamente 7\% marcaron la opción "estoy totalmente de acuerdo", 50\% "estoy de acuerdo en parte" y $38 \%$ "estoy en desacuerdo".

- Con respecto a "Se debe dejar que el cuerpo viva como quiera", aproximadamente 10\% marcaron la opción "estoy totalmente de acuerdo", 44\% "estoy de acuerdo en parte" y $39 \%$ "estoy en desacuerdo".

La concepción del cuerpo como instrumento ya estaba presente en la noción germinal de técnica corporal propuesta por Marcel Mauss (1979, [1936]). Recordemos que las técnicas corporales estaban definidas como la forma en que en cada sociedad los seres humanos hacen uso de su cuerpo en una forma tradicional. Aunque están socio-culturalmente construidas, quien las ejecuta las percibe como un acto técnico, mecánico, físico o físico-químico, y se diferencian de otras técnicas en el hecho de que, en ellas, el cuerpo es el principal instrumento, objeto y medio técnico, aunque pueden incluir también otros instrumentos. Desplegando esta explicación, podemos decir que el hecho de que el cuerpo humano sea el instrumento no es algo menor: el cuerpo no es como cualquier instrumento. En otro tipo de técnicas, las personas, por medio de su cuerpo (o de alguna de sus partes), manipulan un instrumento para modificar un objeto y elaborar un producto. En estos casos, no es necesario que pasen al producto elementos de la materialidad del cuerpo, ni del instrumento; estos no quedan en el producto más que en el hecho de que por medio de ellos ha sido producido. Pero cuando el cuerpo no solo utiliza un instrumento sino que él mismo es un instrumento, también es el objeto hacia el que se dirige la técnica y es el producto de esa actividad. En la danza, en tanto técnica corporal, la persona utiliza su cuerpo como instrumento, lo modifica como objeto y lo construye como producto.

Las técnicas de movimiento que son parte de las distintas danzas que hemos estudiado tienen como fin ser incorporadas, entrar en el cuerpo y formarlo para el movimiento de acuerdo a sus reglas. Como hemos visto en capítulos precedentes, el valor otorgado a la incorporación de técnicas de movimiento específicas varía en cada una de las carreras. También son variables los propósitos de estas técnicas, que van desde lograr ejecutar determinados movimientos con precisión, hasta la búsqueda de la percepción del cuerpo propio para ampliar sus posibilidades de movimiento. Sin embargo, tienen algo en común: la incorporación de las técnicas no es un fin en sí mismo, ni el cuerpo formado en esa técnica es el producto final; el cuerpo formado en esas técnicas es a la vez un medio para la expresión. Un acuerdo general que encontramos entre los informantes/interlocutores es que puede decirse que una técnica ha sido incorporada acabadamente cuando está tan fuertemente incorporada que no es necesario pensar en ella al moverse sino que puede olvidársela para concentrarse en lo que se desea expresar. En palabras de la directora del Ballet Clásico de la Escuela de Danzas Clásicas de La Plata, al explicar la perspectiva que sustentó la creación de tal Ballet: " ni el virtuosismo ni la técnica constituyen finalidades; las técnicas son medios que posibilitan ampliar capacidades para la ejecución, creación y producción artística" (Raggio, 2009).

El cuerpo, como medio de expresión, también lo entiende como un objeto. Un medio es una entidad a través de la cual es posible hacer algo. Es algo que contacta una cosa con otra, un estado con otro. En las danzas que estudiamos, lo que permite hacer ese medio es 
expresarse o expresar algo. De este modo, el cuerpo como medio actúa como mediador entre el sujeto y su expresión. Es un sujeto el que se expresa través de su cuerpo, y este queda establecido como una materialidad que hace que esa expresión no sea inmediata, sino mediada por él. Dicho de otro modo, si el cuerpo es un medio de expresión, entonces es un sujeto el que expresa por medio del control de un objeto, que es su cuerpo.

Lo que olvidan estas nociones es que también el cuerpo es en sí mismo la expresión. El cuerpo no solo es algo con lo que se expresa, no solo expresa algo que proviene de una experiencia subjetiva a través del cuerpo en movimiento, sirviéndose de él, sino que él mismo, en su materialidad y en el modo en que ha sido construido, expresa. Si pretendemos que los estudios sobre danza sirvan para discutir las teorías sobre el cuerpo que lo ven únicamente como una superficie donde se inscribe la sociedad y la cultura, no debemos olvidar que el cuerpo no solo es medio, instrumento, lugar de inscripción -en suma, objeto-, sino que es el lugar donde ocurre la vida. No solo es un espacio habitado por un sujeto, sino que es un lugar vivido, un espacio experimentado, producto y productor de experiencias, representaciones y prácticas. Estas nociones de cuerpo igualmente han surgido en el trabajo de campo: al indagar un poco más con las preguntas y procesar lo que nos sucedía en las instancias de participación directa en las prácticas estudiadas, aparece esta condición más activa del cuerpo, en la que somos una unidad cuerpo-sujeto-cultura. El cuerpo también actúa como medio para construir subjetividad, y es un territorio donde se desarrolla la agencia. Del mismo modo que, en la danza, el cuerpo es un medio y un instrumento que se pone en juego con distintas finalidades, la danza es medio e instrumento para producir determinados cuerpos y sujetos y, por medio de ella, pueden construirse corporalidades y subjetividades que desbordan el control.

\section{REFERENCIAS}

Duncan, Isadora. Mi vida. Ciudad de La Habana: Editorial Arte y Literatura, 1985 [1921].

Foucault, Michel. Las palabras y las cosas. Una arqueología de las ciencias humanas. Buenos Aires: Siglo XXI Editores, 2008 [1966].

Graham, Martha. La memoria ancestral. Barcelona: Circe Ediciones, 1995 [1991].

Itelman, Ana. "Archivo Itelman". comp. Rubén Szuchmacher,). Buenos Aires: EUDEBA, 2002.

Jackson, Michael. Paths toward a clearing: Radical Empiricism and Ethnographic Inquiry. Indiana: Indiana University Press, 1989.

Kriner, Dora. Ensayos sobre el ballet. Buenos Aires, Ricordi Americana, 1964.

Mauss, Marcel. “Las técnicas del cuerpo". En Sociología y antropología. Madrid, Tecnos, 1979 [1936].

Mora, Ana Sabrina. "El cuerpo en la danza desde la antropología. Prácticas, representaciones y experiencias durante la formación en danzas clásicas, danza contemporánea y expresión corporal" [En línea]. Tesis doctoral, Universidad Nacional de La Plata: La Plata, 2011. Repositorio Institucional Central de la UNLP (SeDiCl) http://hdl.handle.net/10915/27179 (Acceso: 11 de junio de 2013).

Raggio, Elisa. Entrevistada por Ana Sabrina Mora. 4 de junio, 2009.

Stokoe, Patricia. Expresión corporal: arte, salud y educación. Buenos Aires: ICSA/Humanitas, 1990. 


\section{Cómo citar este artículo:}

Mora, Ana "El cuerpo como medio de expresión y como instrumento de trabajo: dualismos persistentes en el mundo de la danza". Cuadernos de Música, Artes Visuales y Artes Escénicas, 10 (1), 115-128, 2015. http://dx.doi.org/10.11144/Javeriana.mavae10-1.cmei 